\title{
Latent inhibition as a performance deficit resulting from CS-context associations
}

\author{
NICHOLAS J. GRAHAME, ROBERT C. BARNET, LISA M. GUNTHER, and RALPH R. MILLER \\ State University of New York, Binghamton, New York
}

\begin{abstract}
Treatments that attenuate latent inhibition (LI) were examined using conditioned suppression in rats. In Experiment 1, retarded conditioned responding was produced by nonreinforced exposure to the CS prior to the CS-US pairings used to assess retardation (i.e., conventional LI). In Experiment 1a, retarded conditioned responding was induced by preexposure to pairings of the CS and a weak US prior to retardation-test pairings of the CS with a strong US (i.e., Hall-Pearce [1979] LI). Both types of $\mathrm{LI}$ were attenuated by extensive exposure to the training context (i.e., context extinction) following the CS-US pairings of the retardation test. Experiment 2 examined the specificity of the attenuated LI effect observed in Experiment 1. After preexposure to two different CSs in two different contexts, each CS was paired with a US in its respective preexposure context. One of the two contexts was then extinguished. This attenuated LI to a greater degree for the CS that had been trained in the extinguished context. Experiment 3 differentiated the roles in LI of CS-context associations and context-US associations. Following preexposure to the $\mathrm{CS}$ in the training context, LI was reduced by further exposure to the CS outside the training context. This observation was interpreted as implicating the CS-context association as a factor in $\mathrm{LI}$. Thus, the results of these experiments suggest that $\mathrm{L}$ is a performance deficit mediated by unusually strong CS-context associations. Implications for Wagner's (1981) SOP model and Miller and Matzel's (1988) comparator hypothesis are discussed.
\end{abstract}

Latent inhibition (LI), also known as the CS-preexposure effect, is a deficit in Pavlovian responding to a reinforced conditioned stimulus (CS) observed when subjects are exposed to nonreinforced presentations of that CS prior to reinforced training (e.g., Lubow, 1973). Numerous theoretical explanations of $\mathrm{LI}$ have been proposed, almost all of which have presumed that LI results from a failure by subjects to acquire the CS-unconditionedstimulus (US) association (see, e.g., Lubow, Schnur, \& Rifkin, 1976; Mackintosh, 1975; Pearce \& Hall, 1980; Wagner, 1981). Typically, these theories propose that the nonreinforced pretraining exposure to the target CS decreases attentional or memorial processing of the CS, which impairs the subject's ability to associate the CS with a US when these elements are later paired.

However, theories explaining LI as solely the result of impaired acquisition have been challenged by recent findings which indicate that responding to the CS can be increased by various treatments administered after the

\footnotetext{
This research was made possible by funds from National Institute of Mental Health Grant 33881 and the SUNY-Binghamton Center for Cognitive and Psycholinguistic Studies. Experiments 1, 1a, and 3 were executed in partial fulfillment of the requirements for the $\mathrm{PhD}$ for N.J.G., who was supported by a SUNY-Binghamton Dissertation Year Fellowship. Thanks are due Patricia DiLorenzo, Wesley J. Kasprow, Norman E. Spear, David S. Wilson, and Hua Yin for their comments on a preliminary version of this manuscript. Requests for reprints should be addressed to R. R. Miller, Department of Psychology, SUNY-Binghamton, Binghamton, NY 13902-6000 (e-mail: rmiller@ bingvmb.cc.binghamton.edu).
}

retardation-test CS-US pairings. These include a "reminder treatment," which consists of the US administered alone outside the training context (Kasprow, Catterson, Schachtman, \& Miller, 1984), and testing that is extensively delayed after the CS-US pairings (Kraemer, Randall, \& Carbary, 1991). These observations suggest that CS preexposure produces a reversible performance failure, whereby subjects are slow to respond in accord with the novel contingency encountered during the CSUS pairings of the retardation test, but in fact are able to adequately learn the CS-US association during these pairings.

One potential explanation of $\mathrm{LI}$ as a performance failure is provided by the comparator hypothesis (Miller \& Matzel, 1988; Miller \& Schachtman, 1985), which is a response rule for the expression of acquired associations rather than a model for the acquisition of associations. In the framework of the comparator hypothesis, conditioned responding is thought to reflect a comparison between the associative strength of the CS and the associative strength of the context in which that CS was trained. Specifically, the comparator hypothesis posits that there are three associative links which together provide the basis for conditioned responding: (1) the CSUS association; (2) the association between the CS and the training context; and (3) the association between the training context and the US. (The relevant context continues to be the CS training context even if a test trial occurs in a different context.) During testing, presentation of the CS evokes two representations of the US. The first 
is produced directly by the CS-US association (Link A); the second is produced indirectly, the CS activating a representation of the training context (Link B), which in turn activates its own representation of the US (Link C). When the strength of the US representation activated directly by the CS is large relative to the strength of the US representation activated indirectly by Links B and C, excitatory responding is expected; when the reverse is true, inhibitory responding is expected. Thus, excitatory conditioned responding to a CS is assumed to be inversely related to the strength of the CS-context and context-US associations. The comparator hypothesis has proven effective in explaining conditioning such phenomena as overshadowing (Matzel, Schachtman, \& Miller, 1985), the US-preexposure effect (Matzel, Brown, \& Miller, 1987), and conditioned inhibition (Hallam, Matzel, Sloat, \& Miller, 1990; Kasprow, Schachtman, \& Miller, 1987).

An explanation of LI in the framework of the comparator hypothesis arises from the possibility that pretraining exposure to the CS results in a stronger CScontext association (i.e., Link B) than would exist without CS preexposure. Subsequent acquisition of a CS-US association during the retardation test would not, according to this explanation, be affected. However, a strong CS-context association would enhance activation of the US representation mediated by Links B and C, thereby causing attenuated responding to the CS. In other words, those subjects that receive CS-preexposure treatment during the first phase of an LI experiment develop stronger $\mathrm{CS}$-context associations than the subjects that receive context-alone preexposure. During the CS-US pairings of the retardation test, both the training context and the CS acquire the ability to evoke US representations. Moreover, these are presumed to be equivalent in preexposed and nonpreexposed subjects. However, the stronger CS-training-context associations of the CS-preexposed subjects cause them to have a more robust indirectly activated representation of the US via Links B and C. According to the comparator hypothesis, greater reactivation of this CS-context association (and, consequently, of the context-US association) attenuates excitatory responding to the CS.

If this view is valid, extinction of the training context prior to the retardation-test CS-US pairings should degrade the CS-context association, thereby decreasing LI by reducing the ability of the CS to activate the representation of the training context during testing. Similarly, extinction of the training context following the retardation-test CS-US pairings should reduce both the CS-context and the context-US associations. Therefore, this manipulation would be predicted to be effective from the standpoint of the comparator hypothesis because extinction of either of these associations would enhance responding to the CS. Furthermore, to the extent that extinguishing the training context after the CS-US pairings of the retardation test proves effective in enhancing responding to the $\mathrm{CS}$, it would demonstrate that, rather than CS preexposure affecting acquisition of the
CS-US association during the retardation test, performance is important in mediating LI.

Notably, the effect of extinguishing the training context on responding to the preexposed CS during testing would be expected to occur regardless of whether testing occurs in the preexposure/training context or in a different, test context. The ability of the comparator stimulus to influence responding via comparator mechanisms is not thought to be affected by the location of testing (Miller \& Schachtman, 1985). Even when testing occurs outside the training context, the comparator context is apparently the representation of the training context activated by the CS during testing, not the representation of the context activated directly by the testcontext cues (Kasprow et al., 1987).

Four experiments are presented here with the intent of furthering our understanding of the role of comparator processes in LI. Experiment 1 used the conventional LI procedure, in which subjects are given nonreinforced exposure to the target CS prior to the CS-US pairings of the retardation test. Experiment la used a variant of the conventional LI procedure. During the CS-preexposure phase, the initial CS presentations were paired with a weak US. Then, during the retardation phase, the CS was paired with a strong US. This treatment has been shown to yield a response failure similar to that seen following simple nonreinforced CS preexposure (Hall \& Pearce, 1979). If posttraining extinction of the preexposure/ training context can successfully reverse both types of LI deficits, this would suggest that these two types of LI arise from similar associative processes. Experiment 2 sought to determine whether the effect of posttrainingcontext extinction on CS responding seen in Experiment 1 was specific to the particular context in which the CS was preexposed and trained. Finally, Experiment 3 investigated the associative linkage underlying $\mathrm{LI}$, and sought to provide direct evidence concerning the role of CS-context associations.

\section{EXPERIMENT 1}

The purpose of this experiment was to determine whether extinction of associations to the training context following both $C S$ preexposure and the subsequent CS-US retardation-test pairings would attenuate LI. A $2 \times 2$ factorial design was used in which subjects received either CS preexposure (LI) or equivalent context preexposure $(\mathrm{C})$, and subsequently received either training context extinction treatment (EXT) or no extinction of the training context [HC (home cage)]. Testing occurred in an associatively neutral test context, (1) to minimize differences in responding to the CS based on associative summation of the test context with the associative strength of the CS, and (2) to avoid the possibility that testing in the training context might partially reactivate the CS representation prior to the presentation of the CS on the test trial, which might differentially alter responding in the CS preexposed and nonpreexposed groups. 


\section{Method}

\section{Subjects}

The subjects were 48 ( 24 male, 24 female) naive Sprague Dawley-descended rats bred in our own colony from Holtzman stock (Madison, WI). Weight ranges were $265-430 \mathrm{~g}$ for males and $195-282 \mathrm{~g}$ for females. Subjects were individually housed in wire-mesh cages. All groups $(n \mathrm{~s}=12)$ were counterbalanced for sex and conditioning chamber. Prior to the study, all subjects were progressively deprived of water and, by Day 1 , were limited to $10 \mathrm{~min}$ per day of home-cage access to water provided $18-22 \mathrm{~h}$ prior to any treatment scheduled for the following day. Purina Laboratory Chow was freely available in the home cages.

\section{Apparatus}

The apparatus consisted of 12 conditioning chambers measuring $30 \times 28 \times 27 \mathrm{~cm}$ (length $\times$ width $\times$ height). On one wall beginning just above floor level, there was a $5.4 \times 3.5 \times 4.0 \mathrm{~cm}$ (height $X$ weight $\times$ depth) niche containing a water-filled lick tube. The lick tube was left-right centered in the niche $3.5 \mathrm{~cm}$ above the floor and protruded $1.7 \mathrm{~cm}$ from the back of the niche. A photobeam $1.0 \mathrm{~cm}$ in front of the lick tube was used to monitor drinking. All chambers had clear Plexiglas ceilings and side walls; front and back walls were metal. Chamber floors were 4-mm stainless steel grids spaced $1.6 \mathrm{~cm}$ apart. All chambers were housed in sound- and light-attenuating environmental cubicles. Each chamber was equipped with a \#1820 houselight, a chamberwall speaker which could deliver a white noise $6 \mathrm{~dB}(\mathrm{C})$ (SPL) above a background hum of $72 \mathrm{~dB}(\mathrm{C})$, and a 15-W, 120-V (AC) light positioned just above the clear Plexiglas ceiling of the operant enclosure. A $1.5-\mathrm{mA}, 500$-msec constant-current footshock could be delivered through the grid floor. The shock was scrambled via NE-2 neon bulbs attached to the grids in series with a $1-\mathrm{M} \Omega$ resistor. Methyl salicylate (two drops) could be applied to a wooden block inside each environmental cubicle to provide an olfactory contextual cue.

Two contexts were used: Context Train consisted of one of the chambers described above, with the houselight and 120-V (AC) light switched off and no odor cue present; Context Test consisted of a different one of the above chambers, with the houselight and 120-V (AC) light switched on and the methyl salicylate odor cue present. Prior experiments in this laboratory have demonstrated the efficacy of this combination of odor, enclosure, and lighting in creating two discriminable contexts.

\section{Procedure}

Acclimation to Context Test. On Day 1, the subjects were placed in Context Test for $60 \mathrm{~min}$ with lick tubes present.

Acclimation to Context Train and CS preexposure. The subjects were placed in Context Train for $60 \mathrm{~min}$ per day on Days 2-5. Lick tubes were present. During each session, half of the subjects (Groups LI-HC and LI-EXT) were given thirty 15-sec pseudorandomly distributed nonreinforced white-noise presentations, while the other half (Groups C-HC and C-EXT) were given the same context exposure without the white-noise presentations.

Retardation test pairings. On Day 6, lick tubes were removed. All subjects were placed in Context Train for $60 \mathrm{~min}$, during which they received four 15 -sec, pseudorandomly distributed presentations of the white-noise $\mathrm{CS}$, each coterminating with the 1.5-mA, 500-msec footshock US.

Context extinction. On Days 7-11, subjects in Groups LI-EXT and C-EXT were given daily 120-min sessions in Context Train, with no presentation of nominal stimuli and no lick tubes present. Subjects in Groups LI-HC and C-HC remained in the home cage, but received handling equivalent to that of Groups LI-EXT and C-EXT.

Reacclimation. On Day 12, all subjects were placed in Context Test for $60 \mathrm{~min}$ with lick tubes present in order to reestablish a stable baseline for licking behavior.
White-noise test. On Day 13, all subjects were tested for suppression to the white noise during an 11-min session in Context Test. The white noise was presented to each subject after 5 cumulative sec of licking had been completed, thereby ensuring that all subjects were licking at $\mathrm{CS}$ onset. The white noise remained on until an additional 5 cumulative sec of licking were completed or until $600 \mathrm{sec}$ in the presence of the CS had elapsed. This procedure imposed a 600 -sec ceiling on lick-suppression scores. Subjects were tested in the same manner again on Day 15.

Context Train test. On Day 14, all subjects were placed in Context Train for a 10-min session. Latencies to complete $5 \mathrm{cu}$ mulative sec of licking were recorded. No CSs or USs were presented during this session. This procedure imposed a 600 -sec ceiling on the scores obtained. Latency scores from Days 13, 14, and 15 were subsequently converted to common log sec to better accommodate the assumptions of parametric statistics. A $p$ value of .05 was established for statistical significance.

\section{Results and Discussion}

Extinction of the training context was seen to enhance conditioned responding to the CS in LI animals but not in $\mathrm{C}$ animals. Thus, posttraining extinction of the training context appears to have reduced LI. The following analyses support and illuminate this conclusion.

Data from the first 5 lick sec on Day 13 [i.e., before the onset of the CS in Context Test (see Figure 1)] were analyzed by a 2 (preexposure condition: LI or C) $\times 2$ (context extinction condition: EXT or $\mathrm{HC}$ ) analysis of variance (ANOVA). This revealed a main effect of context extinction $[F(1,44)=7.61]$. This effect presumably arose from a failure of subjects to completely differentiate between Context Train (in which context extinction occurred) and Context Test. No main effect of preexposure was observed $[F(1,44)=0.01]$, nor was there a context extinction $\times$ preexposure interaction $[F(1,44)=$ 2.83 . A similar analysis conducted on pre-CS data from the Day 15 test failed to reveal a main effect of either context extinction $[F(1,44)=0.97]$ or preexposure

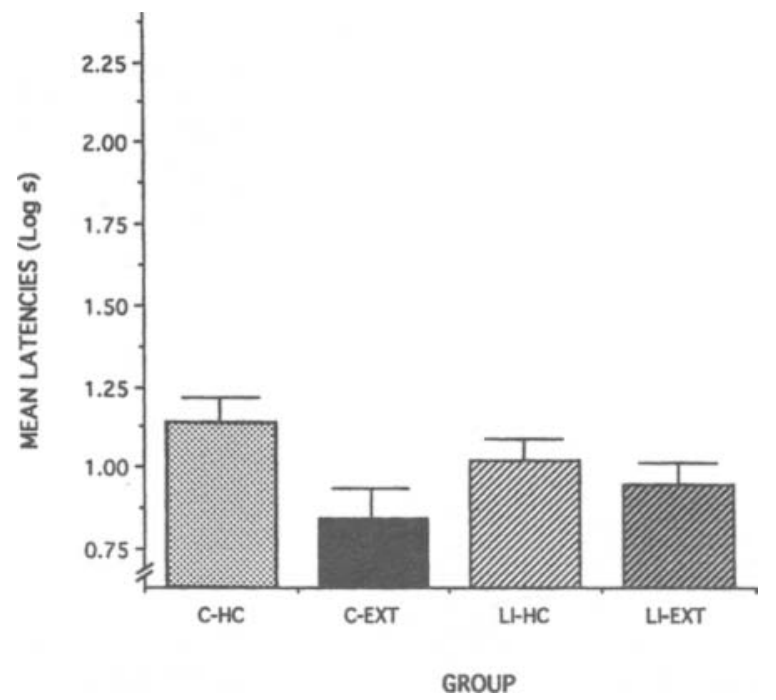

Figure 1. Mean latencies to complete the first 5 cumulative sec of drinking in Context Test on Day 13 of Experiment 1. Error bars indicate $S E M$. 


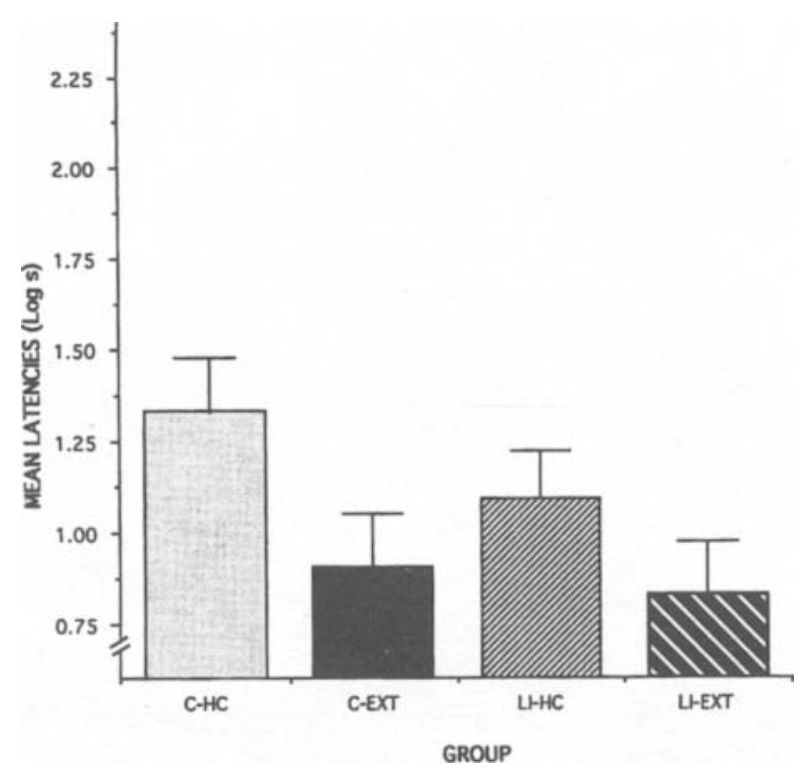

Figure 2. Mean latencies to complete the first 5 cumulative sec of drinking in Context Train on Day 14 of Experiment 1. Prior to this test, Groups C-EXT and LI-EXT received nonreinforced exposure to Context Train. Error bars indicate SEM.

$[F(1,44)=0.72]$, or a context extinction $\times$ preexposure interaction $[F(1,44)=1.35]$.

Lick latencies from the training-context test on Day 14 (see Figure 2 ) were analyzed by a 2 (preexposure condition: LI or C) $\times 2$ (context-extinction condition: EXT or HC) ANOVA, which revealed a main effect of context extinction $[F(1,44)=5.76]$. There was no main effect of preexposure $[F(1,44)=1.17]$, nor was there a context extinction $\times$ preexposure interaction $[F(1,44)=$ $0.30]$. Thus, fear of the training context appeared to be reliably decreased by the extinction manipulation.

Of greatest importance were the data from the whitenoise tests on Days 13 and 15 (see Figure 3). These data were analyzed using a 2 (preexposure condition: LI or C) $\times 2$ (context extinction condition: EXT or HC) $\times 2$ (test day: 13 or 15) ANOVA, in which test day was within subjects. Although there was a main effect of test day $[F(1,44)=51.33]$, which presumably arose from CS extinction during the first nonreinforced test on Day 13, there were no interactions between test day and any of the other factors (all $p \mathrm{~s}>.25$ ).

There was a main effect of preexposure, $[F(1,44)=$ 8.22]. More importantly, a preexposure $\times$ context extinction interaction $[F(1,44)=5.41]$ showed that the effect of context extinction depended on whether subjects had received CS preexposure prior to the CS-US retardation-test pairings. As can be seen in Figure 3, this interaction arose from the tendency of the context-extinction manipulation to decrease the suppression scores of $C$ subjects while increasing the suppression scores of LI subjects.

These data indicate that extinction of associations to the training context between the CS-US pairings and CS testing attenuates the deficit induced by CS-preexposure treatment. No increase in the latency to respond to the CS as a result of extinction of the training context was seen in those subjects not given nonreinforced preexposure to the CS; in fact, a nonsignificant tendency for context extinction to decrease the rate of responding to the CS in C subjects was observed. This tendency, which likely contributed to the interaction between context ex-

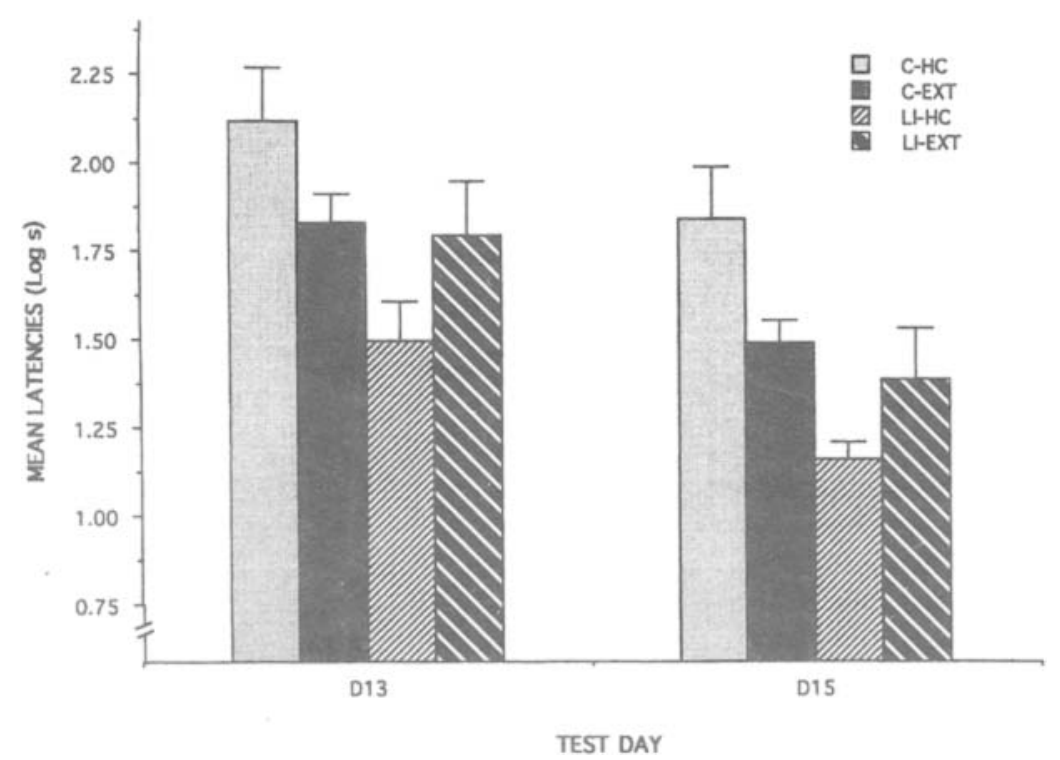

Figure 3. Mean latencies to complete cumulative seconds 5-10 of drinking in the presence of the white noise in Context Test on the two CS test days of Experiment 1. Groups LI-HC and LI-EXT received CS preexposure. Following CS-US pairings, Groups C-EXT and LI-EXT were given nonreinforced exposure to the training context. Error bars indicate $S E M$. 
tinction and preexposure, presumably arose from incomplete differentiation of training and testing contexts. Specifically, conditioned excitation of Context Train probably generalized to a limited degree to Context Test, and on the CS test trial, that excitation may have associatively summated with excitation elicited by the CS. Consequently, extinction of Context Train would be expected to slightly reduce the apparent excitatory value of the CS in Context Test.

Therefore, the observed suppression to the CS on the test trials might reflect some associative summation of Context Test with the CS. This view is consistent both with the direct test of suppression to Context Test, in which there was less suppression observed in the groups that had Context Train extinguished than there was in the nonextinction groups (see Figure 1), and with the CSsuppression tests for the $\mathrm{C}$ groups (i.e., no CS preexposure), in which there was less suppression to the CS following extinction of Context Train than there was with no extinction of Context Train (see Figure 3). Extinction of Context Train increased the rate of responding to the CS only in those subjects whose responding was impaired by CS preexposure. Furthermore, the observed increase in CS response rates in LI subjects was present despite the reduced suppression to Context Test seen prior to CS onset. In all groups, notably, responding was far from the maximum possible (i.e., $2.78 \mathrm{log}$ sec), suggesting that a ceiling effect in $C$ subjects was not the reason that their suppression scores failed to increase following extinction of Context Train.

The present results are consistent with the comparator hypothesis (Miller \& Matzel, 1988). Within this framework, the increase seen in responding to the CS in Group LI-EXT relative to Group LI-HC following extinction of the preexposure/training context may have been due to either a decrease in CS-context associations or a decrease in context-US associations, or to both. That extinction of the training context reduced suppression to the training context (in the absence of the CS) suggests that, at least in part, the operation was effective in enhancing responding to the CS as a result of a reduction in context-US associations. Additionally, presentation of the training context without the CS present might also be expected to extinguish associations between the training context and the CS. However, since no assay of CS-context associations was possible in the present experiment, we are unable to determine precisely the relative impact of decreased context-US associations and decreased CS-context associations. Nevertheless, whatever mechanism accounts for the efficacy of training-context extinction, these data demonstrate that conventional LI, induced by nonreinforced CS preexposure, represents a reversible performance deficit rather than an acquisition failure.

\section{EXPERIMENT 1a}

Hall and Pearce (1979) reported the results of a series of experiments in which subjects were exposed to pair- ings of a target CS with a weak-footshock US in Phase 1, while control subjects received similar pairings with a nontarget CS. During Phase 2, all subjects received a pairing of the target CS with a strong shock. Those subjects that had received target CS-weak US pairings in Phase 1 were retarded in their acquisition of conditioned responding in comparison with control subjects. This effect, hereafter referred to as Hall-Pearce $L I$, has since been replicated by other researchers (e.g., Kasprow, Schachtman, \& Miller, 1985). Hall-Pearce $\mathrm{LI}$ is seemingly similar to conventional $\mathrm{LI}$ in that exposure to the CS during Phase 1 retards the potential of the CS to elicit excitatory responding during Phase 2.

Hall and Pearce's (1979) results have been interpreted as providing support for Pearce and Hall's (1980) model of conditioning, which posits that in this situation, the consistent outcome of the CS during Phase 1 impairs the subject's ability to associate the CS with the new, stronger US during Phase 2. Thus, in the framework of the Pearce and Hall (1980) model, Hall-Pearce LI is an irreversible acquisition deficit. However, if Hall-Pearce LI is indeed similar to conventional LI, the observed retardation might also result more from a performance deficit rather than from an acquisition deficit. This suggests that extinction of the training context following Phase 2 would increase the response potential of the CS, either by decreasing the CS-context association or by decreasing the context-US association. The purpose of Experiment la was to test the efficacy of training-context extinction on Hall-Pearce LI. The basic design was similar to that of Hall and Pearce (1979); however, half of the subjects were given an additional treatment in which associations to the training context were extinguished after presentation of the CS-US pairings that were used to assess retardation. Conditioned suppression of barpressing was used in the present experiment to allow assessment of Phase 1 conditioning (i.e., CS-weak US), which would not have been feasible with a lick suppression procedure, such as that used in Experiment 1.

\section{Method}

\section{Subjects}

The subjects were 48 rats of the same description and deprivation conditions as in Experiment 1. Weight ranges were $325-490 \mathrm{~g}$ for males and $240-320 \mathrm{~g}$ for females. Subjects were assigned to one of four groups $(n s=12)$ counterbalanced for sex and conditioning chamber.

\section{Apparatus}

The chambers used in Experiment 1 served as the apparatus in Experiment 1a, except that an operant lever and a recessed water dipper with a 0.4-cc cup were added and the lick tube of Experiment 1 was removed. Additionally, the chamber speaker could deliver either a $6 / \mathrm{sec}$ click train $6 \mathrm{~dB}(\mathrm{C})$ above background or a compound tone $(3000$ and $3200 \mathrm{~Hz}) 8 \mathrm{~dB}(\mathrm{C})$ above background. The white noise of Experiment 1 was not used in this study. The footshock was either $0.3 \mathrm{~mA}$ for $100 \mathrm{msec}$ (weak US) or $1.2 \mathrm{~mA}$ for $1 \mathrm{sec}$ (strong US). Contexts Train and Test were differentiated in the same manner as in Experiment 1. 


\section{Procedure}

Acclimation to Context Test and shaping. Subjects were placed in Context Test on Days 1-3 for $60 \mathrm{~min}$. On Day 1, subjects received fixed-time 120 -sec noncontingent water reinforcement in addition to continuous reinforcement (CRF) for barpressing. When given, water remained available in the filled dipper until it was consumed. On Days 2 and 3, subjects received water on a CRF schedule for barpressing.

Acclimation to Context Train and shaping. On Day 4, the subjects were placed in Context Train, where they received CRFbarpress training. Subjects were switched to variable-interval 20-sec reinforcement for barpressing on Days 5-7. This schedule was used for the remainder of the experiment. All sessions were $60 \mathrm{~min}$ in duration.

Conditioning with the weak US in Context Train. All subjects received daily 60-min sessions on Days 8-12 (Phase 1 conditioning). During these sessions, half of the subjects in each of the four groups received five pseudorandomly distributed $60-\mathrm{sec}$ presentations of the click CS. The other half of each group received equivalent exposure to the tone CS. Thus, the target CS (presented to Groups LI-HC and LI-EXT) and nontarget CS (presented to Groups C-HC and C-EXT) were counterbalanced for physical stimulus. All presentations both of the clicks and of the tone coterminated with the weak footshock. Each CS presentation during this phase and all subsequent CS presentations in the experiment were preceded by a 2-min stimulus-free period to allow assessment of baseline barpress rate for calculation of suppression ratios.

Conditioning with the strong US in Context Train. Phase 2 conditioning on Day 13 consisted of one 60-min session in Context Train. All subjects received one 60-sec presentation of either the clicks or the tone (i.e., target CS), coterminating with the 1-sec strong US. Subjects in Groups LI-HC and LI-EXT received the same CS as on Days 8-12, while subjects in Groups C-HC and CEXT received the CS opposite to that which they had experienced on Days 8-12.

Context Train extinction. On Days 14-18, subjects in Groups C-EXT and LI-EXT received daily 120-min sessions in Context Train with no CSs or USs presented. The remaining subjects stayed in the home cage, but received equivalent handling.

Reacclimation. On Day 19, all subjects spent $60 \mathrm{~min}$ in Context Test with no nominal CSs or shock USs presented. This session was intended to restabilize baseline barpress rates for the test day.
CS Test in Context Test. During a 15-min session on Day 20 , all subjects were given three 60 -sec, nonreinforced presentations of their target CS. Barpresses emitted during a 2-min, stimulusfree period immediately prior to each CS presentation, as well as barpresses emitted during each CS presentation, were recorded.

All barpress data were converted to a suppression ratio, which was calculated using the formula $\mathrm{A} /(\mathrm{A}+0.5 \mathrm{~B})$, where $\mathrm{A}$ represented the number of barpresses made during the $1-\min C S$ and $B$ represented the number of barpresses made during the 2 -min window that preceded the 1 -min CS.

\section{Results and Discussion}

Extinction of the training context was found to augment conditioned responding in Hall-Pearce LI animals, but not in $\mathrm{C}$ animals. The following analyses provide support for this conclusion.

Analyses conducted on barpress data from Phase 1 yielded no differences between any of the groups on any Phase 1 training session (Days 8-11; all $p \mathrm{~s}>.10$ ). As can be seen in Figure 4, all groups showed modest suppression of responding to their respective CSs as a result of Phase 1 training.

Data from the CS test on Day 20 are depicted in Figure 5. These data were analyzed by a 3 (test trial: 1,2 , or 3 ) $\times 2$ (preexposure condition: $\mathrm{C}$ or $\mathrm{LI}) \times 2$ (context extinction condition: $\mathrm{HC}$ or EXT) ANOVA, in which test trial was within subjects and the other two factors were between subjects. Extinction of conditioned responding over the three nonreinforced test trials was revealed by a main effect of test trial $[F(2,82)=31.78]$; however, there were no interactions of test trial with either preexposure or context extinction (all $F \mathrm{~s}<1$ ).

The same $2 \times 2 \times 3$ ANOVA showed a main effect of preexposure $[F(1,41)=9.58]$. The main effect of context extinction did not reach significance $[F(1,41)=2.26]$. Most important was the finding of an interaction between preexposure and context extinction $[F(1,41)=4.38]$,

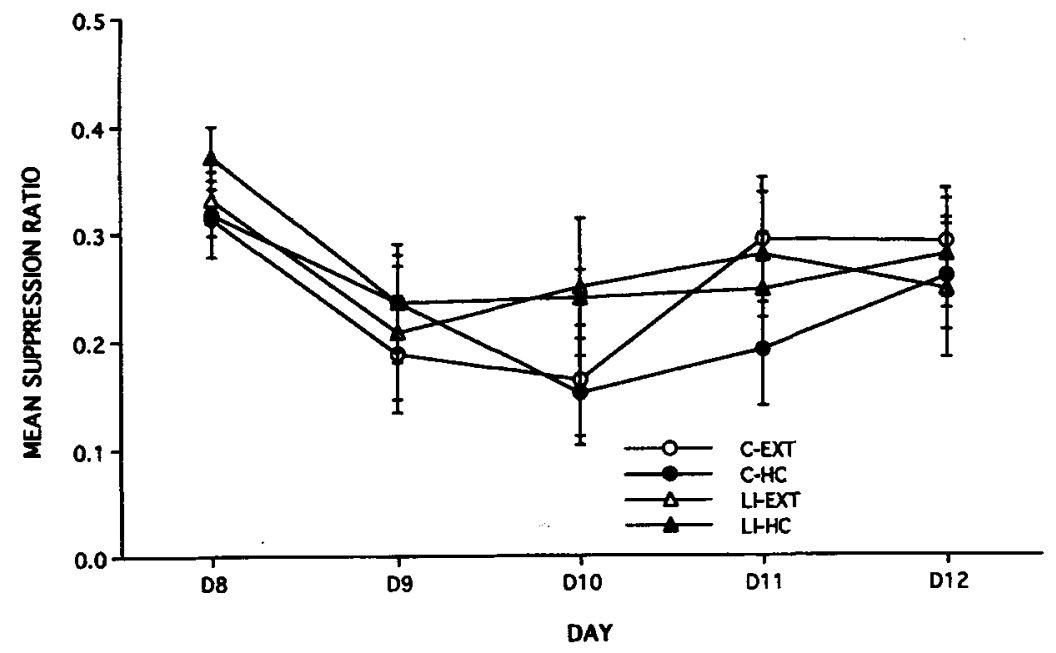

Figure 4. Daily mean suppression ratios to the target CS for Groups LI-HC and LI-EXT and to the nontarget CS for Groups C-HC and C-EXT during Phase 1 of Experiment 1a. Both CSs were presented 5 times daily, reinforced each time with a weak footshock. Error bars indicate $S E M$. 


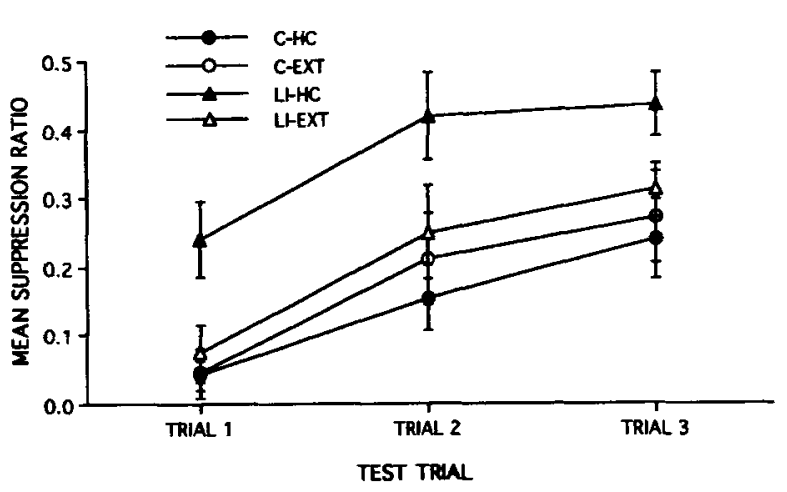

Figure 5. Mean suppression ratios to the target CS on Day 20 of Experiment 1a. Following their respective Phase 1 pretraining, all groups received a single pairing of the target $\mathrm{CS}$ and strong footshock in Phase 2. Subsequently, Groups C-EXT and LI-EXT received nonreinforced exposure to the training context. Error bars indicate $S E M$.

which indicated that the effect of preexposure was present only for those subjects that had not received postconditioning extinction of the training context. As can be seen in Figure 5, extinction of the training context in Group LI-EXT following the CS-strong US pairing increased responding to the CS (i.e., decreased the suppression ratio) to a level close to that seen in Groups C$\mathrm{HC}$ and $\mathrm{C}-\mathrm{EXT}$, indicating almost complete recovery of responding to the target CS.

These data suggest that Hall-Pearce LI, like the conventional $\mathrm{LI}$ effect, represents a reversible performance deficit rather than a failure of subjects to learn an association between the CS and the strong shock in Phase 2, as is suggested by the Pearce and Hall (1980) model. To our knowledge, this is the first demonstration that HallPearce LI is due at least in part to a performance failure. That posttraining extinction of the training context proved effective in reversing the performance deficit seen in Hall-Pearce LI animals is consistent with the view that mechanisms posited by the comparator hypothesis to account for conventional LI are also responsible for the Hall-Pearce LI effect.

According to the comparator hypothesis, the interaction between LI treatment and extinction treatment is a result of context exposure during the extinction phase causing greater attenuation of CS-context associations and/or context-US associations in LI animals than in C animals. ${ }^{1}$ Unfortunately, compared with lick suppression, conditioned suppression of barpressing, while allowing for the assessment of Phase 1 conditioning, represents a relatively poor preparation for the detection of context-US associations (see, e.g., Balsam, 1985; Bouton \& King, 1983). Consequently, measurement of context extinction's effectiveness at reducing context-US associations-or, for that matter, CS-context associations - was not possible in the present experiment. However, most contemporary learning theories would predict that context-US associations in C subjects and LI subjects immediately following Phase 1 training would be equal and small, because for both $\mathrm{C}$ and $\mathrm{LI}$ animals the
CS presented before each weak US would be expected to overshadow substantially the acquisition of associative strength by the training context (see, e.g., Rescorla \& Wagner, 1972). Additionally, competitive learning theories such as the Rescorla-Wagner model would predict that at the end of Phase 2, context-US associations would be somewhat higher in the $\mathrm{C}$ subjects than in the LI subjects. Specifically, relative to $\mathrm{C}$ subjects, for which the target CS was novel at the beginning of Phase 2, the already-trained target CS in the LI subjects should partially block the training context from gaining further associative strength during Phase 2.

The implication of this analysis of the associative strength of the training context for comparator theory is that, as in Experiment 1, differences in context-US associations are an unlikely cause of the poor responding seen in Group LI-HC relative to Group C-HC. Rather, the retardation seen in Group LI-HC may have had more to do with strong CS-context associations, which, according to the comparator hypothesis, should reduce the response potential of the target CS, provided that the training context had some nonzero level of associative strength. One would expect CS-context associations to be strong in LI subjects as a result of Phase 1 conditioning, during which the target CS was presented 25 times in Context Train. By this reasoning, extinction of the training context in Group LI-EXT attenuated LI by extinguishing the CS-context association. Presumably, there was little effect of training-context extinction on C subjects because the CS-context association was already weak, since there had been only one presentation of the target CS in the context for the $\mathrm{C}$ animals, and hence, the CS-context association could not be much further reduced by posttraining context extinction.

\section{EXPERIMENT 2}

One criticism of the comparator hypothesis (Robbins, 1988) has centered on whether the effects of posttraining context extinction are specific to CSs trained in that context. In other words, do comparator effects rely on a specific CS-training-context association and a specific training-context-US association, or do they result from some general, nonassociative process? Limited evidence for the specificity of comparator effects with respect to $\mathrm{LI}$ is seen in the present Experiment 1a, in which posttraining context extinction resulted in increased responding to the CS in Group LI-EXT, which had received the same CS during CS preexposure and the subsequent CS-strong US pairing, but not in Group CEXT, which had received different CSs during CS preexposure and the subsequent CS-strong US pairing. More conclusive evidence for the specificity of comparator effects in general has been seen in a variety of conditioning situations (e.g., conditioned inhibition, local context effects, and overshadowing) in a recent series of experiments by Miller, Barnet, and Grahame (1992). 
Experiment 2 sought to provide evidence for specificity with respect to the recovery of LI observed in Experiment 1 . Subjects were given nonreinforced preexposure to a tone CS in one context and to a white-noise CS in another context. All subjects were then given retardation-test pairings of each CS in its respective preexposure context. Prior to testing the CSs in a third context, animals received extinction of one or the other of the two training contexts. On the first test day, half of the animals were tested on the CS for which preexposure and conditioning context had been extinguished (Condition Test Same), and the other half were tested on the CS for which preexposure and conditioning context had not been extinguished (Condition Test Different). On the second test day, testing conditions were reversed for all subjects. Less LI in Condition Test Same than in Condition Test Different would support the hypothesis that comparator mechanisms affecting LI rely on extinction of a specific CS's training context rather than on extinction of the training context of any CS.

\section{Method \\ Subjects \\ The subjects were 24 ( 12 male, 12 female) rats of the same de- scription and deprivation conditions as those in Experiment 1. Weight ranges were $310-430 \mathrm{~g}$ for males and $190-300 \mathrm{~g}$ for fe- males. Subjects were assigned to one of two test conditions ( $n \mathrm{~s}=$} 12) counterbalanced for sex and conditioning chamber.

\section{Apparatus}

The conditioning chambers used as Context Train in Experiment 1 served as Context Test in the present experiment. In addition to the white-noise stimulus in Experiment 1, a complex-tone ( 3000 and $3200 \mathrm{~Hz}$ ) stimulus, $6 \mathrm{~dB}(\mathrm{C})$ above background, could be presented in each of the chambers.

Two additional enclosures were used for training. Enclosure $R$ was a clear, rectangular, Plexiglas chamber measuring $22.75 \times$ $8.25 \times 13 \mathrm{~cm}$ (length $\times$ width $\times$ height). The floor was constructed of $0.48-\mathrm{cm}$-diam stainless steel rods spaced $1.5 \mathrm{~cm}$ apart, center-to-center. The rods were connected by NE- 2 neon bulbs, which allowed a constant-current footshock to be delivered by means of a high-voltage ac circuit in series with a 1.0-M $\Omega$ resistor. Enclosure $\mathrm{R}$ was dimly illuminated by a $2-\mathrm{W}$ [nominal at $120 \mathrm{~V}(\mathrm{ac})]$ incandescent houselight driven at $56 \mathrm{~V}$ (ac). The houselight was mounted approximately $30 \mathrm{~cm}$ from the center of the enclosure. Six copies of Enclosure R were used, each enclosed in a separate environmental isolation chest.

Enclosure V was a $30-\mathrm{cm}$-long box in the shape of a vertical, truncated V. The enclosure was $28 \mathrm{~cm}$ high and $21 \mathrm{~cm}$ wide at the top, narrowing to $5.25 \mathrm{~cm}$ at the bottom. The floor and $30-\mathrm{cm}$-long sides were constructed of sheet metal. The floor consisted of two 30 -cm-long parallel metal plates, each $2 \mathrm{~cm}$ wide, with a $1.25-\mathrm{cm}$ gap between them. A constant-current footshock could be delivered through the floor by means of a high-voltage ac current in series with a $1.0-\mathrm{M} \Omega$ resistor. The end walls of Enclosure $V$ were black Plexiglas, and the roof was clear Plexiglas. Enclosure $V$ was dimly illuminated by an externally mounted $7.5-\mathrm{W}$ [nominal at $120 \mathrm{~V}$ (ac)] incandescent houselight driven at $56 \mathrm{~V}$ (ac). The houselight was mounted approximately $30 \mathrm{~cm}$ from the center of the animal enclosure. Six copies of Enclosure V were used, each encased in its own environmental isolation chest. Light entered the enclosure primarily by reflection from the roof of the environmental chest. Because of its opaque walls, Enclosure V was illuminated similarly to Enclosure R, despite the use of brighter light bulbs in the former.
Enclosures $\mathrm{R}$ and $\mathrm{V}$ could both be equipped with lick tubes that protruded $2.0 \mathrm{~cm}$ from the far end of a cylindrical drinking niche on a narrow wall of each enclosure. Each niche was $5 \mathrm{~cm}$ in depth, $4.4 \mathrm{~cm}$ in diameter, and $6.5 \mathrm{~cm}$ above the chamber floor. The axis of the niche was perpendicular to the enclosure wall and was leftright centered on the wall. An infrared photobeam, $0.5 \mathrm{~cm}$ in front of the lick tube, was used to detect when the subjects had their heads inserted into the drinking niche. Training with different CSs occurred in each of these two contexts. Within each treatment group, Enclosures $\mathrm{R}$ and $\mathrm{V}$ were counterbalanced with respect to which served as Context $A$ and which served as Context B. Context A was further differentiated by a methyl salicylate odor cue. This was achieved by applying one drop of $100 \%$ methyl salicylate to a small, rectangular block of wood that was placed in each isolation chest housing Context $\mathrm{A}$.

Auditory CSs could be presented in Contexts A and B through separate speakers located on the walls of the environmental chests. The speakers could deliver the previously described white noise and complex tone, both $6 \mathrm{~dB}(\mathrm{C})$ above background. The auditory background in Contexts $A$ and $B$ was a $74-\mathrm{dB}(\mathrm{C})$ ambient sound level created by ventilation fans of the environmental chests. All CSs were $15 \mathrm{sec}$ in duration. All USs were $1.5-\mathrm{mA}, 500-\mathrm{msec}$ footshocks.

\section{Procedure}

Acclimation to Context Test. On Day 1, subjects were placed in Context Test for $60 \mathrm{~min}$, with lick tubes present.

Acclimation to Contexts $A$ and $B$ and $C S$ preexposure. On Days 2, 4, 6, and 8, all subjects were placed in Context $A$ for $60 \mathrm{~min}$, during which they were exposed to thirty 15 -sec nonreinforced tone presentations. On Days 3,5, 7, and 9, all subjects were placed in Context B for $60 \mathrm{~min}$, during which they were exposed to thirty $15-\mathrm{sec}$ nonreinforced white-noise presentations. Lick tubes remained available during these sessions.

Retardation-test pairings. Prior to training, lick tubes were removed from the conditioning chambers. On Day 10 , all subjects were placed in Context $A$ for $60 \mathrm{~min}$, during which they received four reinforced tone presentations. On Day 11, all subjects were placed in Context $B$ for $60 \mathrm{~min}$, during which they received four reinforced white-noise presentations. On both days, the US occurred during the last $0.5 \mathrm{sec}$ of the CS.

Context extinction. On each of Days 12-16, half of the subjects were given $120 \mathrm{~min}$ of exposure to Context $A$ and half were given $120 \mathrm{~min}$ of exposure to Context $\mathrm{B}$. Extinction conditions were counterbalanced with respect to sex, conditioning chamber, and running order.

Reacclimation. Prior to reacclimation, lick tubes were replaced in all conditioning chambers. On Days 17 and 18, all subjects were placed in Context Test for 60 min daily.

Testing. On Day 19, all subjects were tested for suppression to one or the other CS during an 11-min session in Context Test. Half of the subjects in each of the two extinction manipulations (i.e., extinction of Context A or Context B) were tested on the tone CS and the other half were tested on the white-noise CS. Testing with the CS that had been trained in the same context that had been extinguished was designated Condition Test Same, and testing with the other CS was designated Condition Test Different. The method for presenting the CSs and measuring suppression was the same as that used for the white-noise test in Experiment 1. On Day 20, all animals were tested on the CS that was not presented on Day 19.

\section{Results and Discussion}

Less LI was observed when subjects were tested on the CS for which the training context had been extinguished (i.e., Condition Test Same) than when they were 
tested on the CS whose training context had not been extinguished (i.e., Condition Test Different). Thus, it appears that the effect of posttraining context extinction on $\mathrm{LI}$ is specific to CS trained in that context. The following analyses support this conclusion.

The data were analyzed using a 2 (test: same or different) $\times 2$ (order: same first or different first) ANOVA, in which test was within subjects. There was no effect of order $[F(1,22)=0.09]$, nor any interaction between order and test $[F(1,22)=0.05]$. However, there was a main effect of test $[F(1,22)=12.29]$, indicating that the question of which context was extinguished was critical for the attenuation of the LI effect. Specifically, subjects tested on the CS for which the training context had been extinguished (see Figure 6, Test Same) exhibited less LI than those subjects tested on the CS for which the training context had not been extinguished (see Figure 6, Test Different).

These data show that to maximize recovery from LI as a result of posttraining-context extinction, the context in which the target CS was trained must be extinguished; extinction of the training context of another CS was not as effective at enhancing responding to the target CS. (Since there was not a "no-extinction" condition, we do not know whether extinction of a different training context had no effect or merely less effect.) Because the training procedures used were similar to those employed in Experiment 1, the present results support the contention that the recovery from LI seen in Experiment 1 was due to context extinction acting on specific acquired information, rather than being due to some nonspecific

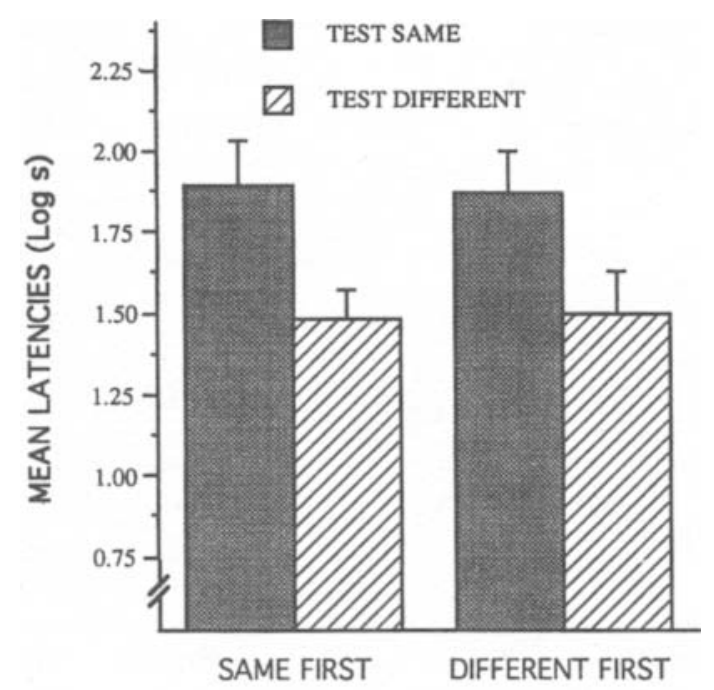

\section{ORDER}

Figure 6. Mean latencies to complete cumulative seconds 5-10 of drinking in the presence of the test CS (tone or white noise) in Context Test on two test days of Experiment 2. Group Same received posttraining context extinction of the same context in which their test CS was preexposed and conditioned. Group Different received posttraining extinction of a different context from that in which their test CS had been preexposed and conditioned. Error bars indicate SEM. performance effect. Although the training procedure used in Experiment 1a was somewhat different, it does not seem likely that a specific associative effect would mediate the recovery seen in conventional LI but would not mediate the recovery seen in Hall-Pearce LI. These data add to the existing body of evidence indicating that comparator effects are specific to a CS-comparatorstimulus dyad (e.g., Miller et al., 1992), thereby furthering the generality of the notion that comparator operations are effective because of their action on an associative linkage specific to a given CS.

\section{EXPERIMENT 3}

One problem inherent in the designs of Experiments 1, $1 \mathrm{a}$, and 2 is the inability to distinguish between CScontext and context-US associations as the source of the retarded responding seen following CS preexposure. As stated earlier, the comparator hypothesis could explain the reduction of LI seen in Experiments 1, 1a, and 2 in terms of either weakened CS-context associations or weakened context-US associations. Limited empirical evidence (i.e., the direct responding to the training context in the absence of context extinction seen in the $\mathrm{HC}$ subjects of Experiment 1) suggested that differences in the context-US association did not mediate the differences seen between $\mathrm{C}-\mathrm{HC}$ and $\mathrm{LI}-\mathrm{HC}$ subjects. Moreover, in the Discussion section of Experiment 1a, some theoretical arguments were presented for the importance of CS-context associations in causing LI.

Additional evidence suggesting the importance of CS-context associations can be found in data from within-compound conditioning experiments. In these experiments, two neutral stimuli are typically simultaneously presented and reinforced (AB-US) and resultant associations between the two stimuli are detected. To the extent that parallels can be drawn between within-compound conditioning experiments and the present LI experiments, in which the discrete CS and context could be viewed as constituting a compound stimulus, the literature concerning within-compound associations can be used to help understand the associative mechanisms responsible for the efficacy of posttraining extinction of the training context. For instance, Rescorla (1983) demonstrated that an A-B association can be weakened if reinforced presentations of $B$ are given following reinforced presentations of the $\mathrm{AB}$ compound. This weakening of the $\mathrm{A}-\mathrm{B}$ association occurred without weakening either the A-US or the B-US associations. These data suggest that, in the present case, a comparator-context-CS association can be weakened following training either in combination with or exclusive of a weakening of the context-US association. Nevertheless, in the absence of direct evidence of CS-context associations causing $\mathrm{LI}$, it is impossible to rule out differences in the strength of the context-US association, or some other factor, as the source of LI and the critical association affected by posttraining extinction of the context. 
Procedurally, there appear to be two ways to extinguish associations between the CS and the training context. One is operational extinction of the training context, as already discussed. The other is operational extinction of the target CS outside the training context. This may extinguish, or at least interfere with, the ability of the CS to reactivate a representation of the training context, which, in the comparator framework, is thought to be necessary for attenuated responding to a preexposed CS. The resulting impaired reactivation of the training-context representation would be expected to reduce the size of the US representation evoked indirectly by the CS during testing, and, therefore, to augment responding to the preexposed CS.

Thus, Experiment 3 attempted to attenuate LI by presenting the target CS outside the training context. If such a manipulation were done following excitatory training, it would result in extinction of the CS-US association, thereby obscuring any comparator effect that might emerge from extinction of the CS-training-context association. Consequently, unlike in Experiments 1 and 1a, CS-context extinction treatment occurred prior to the retardation-test CS-US pairings. Although this design precluded examination of the distinction between learning and performance, any efficacy in attenuating $\mathrm{LI}$ caused by presenting the target CS outside the training context would provide strong evidence of the importance of CS-context associations in LI. This is so because operational extinction of the target CS outside the training context constitutes more CS preexposure, which might be expected (except by theories that emphasize the importance of associations between the CS and the training context in causing LI) to result in a greater deficit in responding.

A second rationale for Experiment 3 was that, despite its advantages in terms of differentiating failures of learning from those of performance, there exists a potential problem with the strategy, used in Experiments $1,1 \mathrm{a}$, and 2 , of extinguishing the training context following the retardation-test CS-US pairings. Specifically, this procedure allows the possibility that extinction of the training context acts on information acquired during the retardation-test CS-US pairings rather than on (or in addition to) the consequences of initial CS preexposure. This is possible because context extinction was given after the retardation-test CS-US pairings. Consequently, the extinction manipulation may have acted uniquely on associative structures acquired during the Phase 2 CS-US pairing(s), rather than on those acquired during the Phase $1 \mathrm{LI}$ treatment. Thus, in addition to determining the relative importance of CS-context and context-US associations in recovery from LI, a second purpose of Experiment 3 was to determine empirically whether it is information gained during Phase 1 or Phase 2 of treatment that is acted on by treatments that promote recovery.

The design of Experiment 3 is presented in Figure 7. CS-preexposure parameters were similar to those of Experiment 1. Groups LI and INT (interference) received

\begin{tabular}{|c|c|c|c|}
\hline GROUP & $\begin{array}{l}\text { PREEXPOSURE } \\
\text { TREATMENT }\end{array}$ & $\begin{array}{l}\text { EXITNCTION } \\
\text { TREATMENT }\end{array}$ & $\begin{array}{l}\text { RETARDATION } \\
\text { PAIFINGS }\end{array}$ \\
\hline LI & $(\text { S1- })_{A}$ & $(\mathrm{~S} 2)_{B}$ & $\langle S:-U S\rangle_{A}$ \\
\hline INT & $\left(\mathbf{S 1 - ) _ { A }}\right.$ & ${ }_{(\mathrm{S} 1-)_{B}}$ & $(S 1-U S)_{A}$ \\
\hline $\mathrm{ACO}$ & $(\cdot)$ & ${ }^{(\mathrm{S} 2-)_{B}}$ & $(\mathrm{~S} 1-\mathrm{US})_{A}$ \\
\hline cs & $(\mathbf{S} 1-)_{A}$ & $(\mathbf{S 1 -})_{\mathrm{A}}$ & $($ (S1-US) \\
\hline
\end{tabular}

Figure 7. The design of Experiment 3. S1 and S2 were two readily distinguishable, counterbalanced stimuli; $A, B$, and $C$ were three different contexts; $(-)$ designates an absence of reinforcement.

CS preexposure in Context A. Group INT then received additional exposure to the target CS, S1, outside the training context--that is, in Context B; Group LI received similar experience, but with a nontarget CS, S2. To demonstrate basic acquisition of responding to $S 1$ for comparison with that of Group LI, another group was included, Group ACQ. These subjects received no preexposure to $S 1$, and during the extinction phase they were exposed to a nontarget CS, S2, in Context B. Finally, Group CS received the same exposure to $S 1$ as Group INT during the preexposure and extinction treatments, but with the additional Sl trials of extinction treatment occurring in Context A. This group was intended to determine whether any recovery of conditioned responding in Group INT, relative to Group LI, depends on the additional S1 experience occurring outside the context of retardation-test S1-US pairings. Finally, all subjects received retardation-test S1-US pairings in Context A, the same context as the initial $\mathrm{S} 1$ preexposure treatment. Only two S1-US pairings were given, instead of the four CS-US pairings of Experiment 1, because of the need to minimize the reestablishment of associations between $\mathrm{S} 1$ and Context A in Group INT. To facilitate acquisition of the S1-US association on these two trials, a stronger US was used than in Experiment 1.

\section{Method}

\section{Subjects}

The subjects were 48 rats ( 24 males, 24 females) of the same description as in Experiment 1. Weight ranges at the beginning of the experiment were $205-330 \mathrm{~g}$ for males and $170-260 \mathrm{~g}$ for females. Groups $(n \mathrm{~s}=12)$ were counterbalanced for sex and conditioning chamber.

\section{Apparatus}

The conditioning chambers used as Contexts Train and Test in Experiment 1 served as Contexts $\mathrm{A}$ and $\mathrm{C}$ in the present experiment. In addition to the white-noise cue from Experiment 1, a complex-tone stimulus, comprised of $3000-$ and $3200-\mathrm{Hz}$ tones, $6 \mathrm{~dB}$ (C) above background, could be presented in each of the chambers. The US was a $2.0-\mathrm{mA}, 2.0$-sec footshock.

An additional set of 12 enclosures, designated as Context B, was used, each one measuring $50.0 \times 16.7 \times 74.5 \mathrm{~cm}$ (length $X$ width $\times$ height). The floor was constructed of $0.64-\mathrm{cm}$ diam stainless steel rods, $1.59 \mathrm{~cm}$ center-to-center, and oriented parallel to the $50-\mathrm{cm}$ long walls. The long walls were constructed of stainless 
steel, while the short walls were made of opaque Plexiglas. These enclosures were located in a moderately illuminated room, which was distinctively different from that housing the nominal training and test enclosures (Contexts $A$ and $C$ ). There were no lick tubes present in Context $\mathrm{B}$. White-noise and complex-tone stimuli, $6 \mathrm{~dB}$ (C) above a $56 \mathrm{~dB}(\mathrm{C})$ background-noise level, could be delivered from an overhead speaker in Context $B$.

\section{Procedure}

Acclimation to Context C. On Day 1, subjects were placed in Context $\mathrm{C}$ for $60 \mathrm{~min}$, with lick tubes present.

Acclimation to Context $A$ and $S 1$ preexposure. Subjects were placed in Context A for 60 min daily on Days 2-5. Lick tubes were present. During each session, Groups LI, INT, and CS were given thirty 15 -sec pseudorandomly distributed presentations of S1. For half of the animals in each group, SI was the white noise, while for the remaining animals, S1 was the complex tone. Group $\mathrm{ACQ}$ was given equivalent exposure to Context $\mathrm{A}$ alone, during which no nominal CS or US was presented.

Operational extinction of S1 or S2. Subjects in Groups LI, INT, and ACQ were placed in Context B for $60 \mathrm{~min}$ daily on Days 6-11. During each session, subjects in Group INT were given thirty 15 -sec presentations of S1. Subjects in Groups LI and ACQ were given equivalent exposure to $S 2$, which was whichever of the noise or tone stimuli that did not serve as $\$ 1$ for these subjects. This treatment was intended to equate these groups for exposure to a stimulus during this phase. Subjects in Group CS received the same exposure to $\mathrm{S} 1$ as subjects in Group INT, but this exposure took place in Context A. Lick tubes were absent during this phase.

Retardation-test pairings. On Day 12, all subjects were placed into Context A for $60 \mathrm{~min}$. All animals received two 15 -sec presentations of $\mathrm{S1}$, each coterminating with the 2-sec footshock US. Presentations occurred 15 and $30 \mathrm{~min}$ after the subject was placed in the training apparatus. Lick tubes were absent during this phase.

Reacclimation. On Days 13 and 14, all subjects were placed into Context $\mathrm{C}$ for $60 \mathrm{~min}$ daily, with lick tubes present, in order to reestablish a stable baseline for licking behavior.

S1 test. On Day 15, all subjects were tested for suppression to $\mathrm{S} 1$ in Context C. S1 was presented to each subject after 5 cumulative sec of licking had been completed, thereby ensuring that all subjects were licking at CS onset. S1 remained on until an additional 5 cumulative sec of licking had been completed or until $900 \mathrm{sec}$ in the presence of the CS had elapsed, imposing a 900-sec ceiling on suppression scores. All latency scores were converted to common log sec to better meet the assumptions of parametric statistics.

\section{Results and Discussion}

Operational extinction of the target CS in a nontraining context following CS preexposure attenuated LI. This argues for the importance of CS-context associations in LI. The following statistical analyses support this conclusion.

One subject in Group ACQ became ill prior to testing and was eliminated from the experiment. Data from the first 5 lick sec on Day 15 (i.e., before the onset of S1) were analyzed by a one-way, four-level ANOVA. This revealed no difference between groups $(F<1)$.

Latencies to complete 5 lick sec in the presence of S1 on Day 15 are presented in Figure 8. A one-way, four-level ANOVA conducted on these data indicated a main effect of treatment $[F(3,43)=11.32]$. A planned comparison between Group LI and Group
ACQ found that CS preexposure in the training context (i.e., Context A) attenuated responding to S1 $[F(1,43)=19.64]$, indicative of LI. Moreover, Group INT showed a larger response to the target CS than either Group CS or Group LI $\left[F_{\mathrm{s}}(1,43)>9.23\right]$. This indicates that the additional exposure to $\mathrm{S} 1$ of Group INT attenuated LI when it was given in a context different from the context in which the initial preexposure and later S1-US pairings occurred. In fact, although Groups INT and ACQ did not differ $(F<1)$, the tendency was toward slightly more responding in Group INT, indicating that recovery of responding to S1 was indeed complete. Given that Group ACQ received no preexposure to $S 1$ and should therefore represent the level of responding to S1 when that stimulus is novel at the beginning of the S1-US pairings, the strong responding to $S 1$ seen in Group INT argues that Group INT's additional experience with S1 completely reversed the impairment of responding to $S 1$ seen in Group LI.

These results indicate that operational extinction of the target CS outside the training context following CS preexposure in the training context decreases LI. This suggests that $\mathrm{LI}$ is caused by associations between the target CS and the training context. In this framework, the additional exposure to $\mathrm{S} 1$ received by Group INT outside Context A attenuated S1-Context A associations, and therefore mitigated LI when S1-US pairings subsequently occurred in Context $\mathrm{A}$.

Results from a wide variety of experiments in LI are at least consistent with LI being caused by CS-context associations. Manipulations which might be expected to reduce CS-context associations, such as extinguishing the training context between CS preexposure and the retardation-test CS-US pairings (Baker \& Mercier,

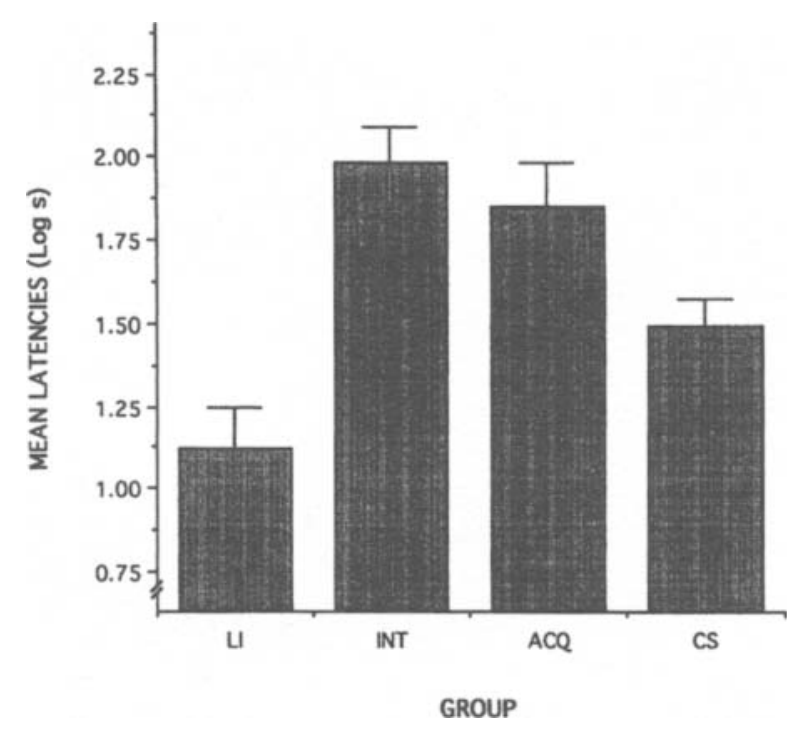

Figure 8. Mean latencies to complete 5 cumulative sec of licking in the presence of S1 on Day 15 of Experiment 3. See text or Figure 7 for details of group treatments. Error bars indicate SEM. 
1982; Wagner, 1979) or changing contexts between CS preexposure and retardation-test conditioning (Channell \& Hall, 1983; Hall \& Honey, 1989) have been shown to attenuate LI. ${ }^{2}$ Another procedure that might also be expected to attenuate $\mathrm{CS}$-context associations is the serial presentation of two stimuli (i.e., $\mathrm{A} \rightarrow \mathrm{B}$ ) during the preexposure phase, relative to preexposure to Stimulus A alone. Such a procedure might allow Stimulus B to overshadow the training context as Stimulus A's primary associate. This procedure has been shown in some circumstances to attenuate LI of Stimulus A relative to that exhibited by subjects preexposed to A alone (Lubow et al., 1976; Szakmary, 1977). When the present data are combined with the results of these prior studies, they offer compelling evidence for an inverse relationship between the strength of CS-context associations and the ability of that CS to control excitatory associative responding following CS preexposure.

The present experiment also suggests that the recovery of responding to the target CS following posttraining context extinction in Experiments 1 and la was mediated by extinction of CS-context associations. In the framework of the comparator hypothesis, operational extinction of the training context in those experiments may have attenuated CS-context associations and/or context-US associations. The fact that responding to a preexposed CS could be recovered in the present experiment by a procedure intended to extinguish $\mathrm{CS}$-context associations implicates these associations in mediating LI in Experiments 1, 1a, and 2.

\section{GENERAL DISCUSSION}

In Experiment 1, conventional LI produced by nonreinforced CS preexposure was reduced by context extinction after all CS-US training was completed. In Experiment 1a, Hall-Pearce LI produced by pairing the CS with a weak US was also attenuated by exposure to the training context after all CS-US pairings. Experiment 2 provided evidence for the importance of a specific CScontext association in mediating the recovery of responding seen in Experiment 1. In Experiment 3, LI was attenuated by operational extinction of the target CS outside the training context. The similar outcomes of Experiments 1 and 1 a suggest that conventional LI and Hall-Pearce LI emerge from similar associative mechanisms. Furthermore, these results seem to indicate the importance of postacquisition processes, as opposed to acquisition processes, in producing both types of LI. Results from Experiment 3 imply that associations between the $\mathrm{CS}$ and the training context formed during CS preexposure serve an important role in producing LI. Together, these experiments suggest that $L I$ is a performance deficit produced by strong CS-context associations.

When combined with the reminder effects of Kasprow et al. (1984) and the spontaneous-recovery effects of Kraemer et al. (1991), the fact that responding to a preexposed CS can be recovered without additional explicit training seems to warrant a reconsideration of whether
LI represents a failure to acquire a CS-US association. Theories such as those offered by Mackintosh (1975), Pearce and Hall (1980), and Wagner (1981), all of which stress attentional changes produced by CS preexposure which in turn result in acquisition deficits, are unable to explain why conditioned responding to the preexposed CS can be restored by postacquisition manipulations. (However, attentional models could explain recovery from LI if it is assumed that attention is necessary not for acquisition, but for later utilization of acquired information.)

On the other hand, the view of LI proposed by the comparator hypothesis (Miller \& Matzel, 1988; Miller \& Schachtman, 1985) predicts the efficacy of extinction of the training context in augmenting responding to the CS. In the present case, the data suggest that increases in responding to the CS emerge from extinction of CScontext associations. In contrast, the comparator hypothesis does not specifically predict the spontaneous recovery from LI reported by Kraemer et al. (1991); rather, it is merely convergent with the conclusion of the latter that, whatever it is, the associative mechanism that causes LI is not one that affects acquisition of a CS-US association. The comparator hypothesis might accommodate Kraemer et al.'s observation by hypothesizing that associations to context (i.e., CS-context or contextUS) are forgotten more rapidly than CS-US associations.

Mitigating against our claim that both Hall-Pearce LI and conventional LI arise from similar mechanisms (as indicated by their parallel sensitivity to posttraining context extinction) is a recent report by Young and Fanselow (1992). In their experiment, the opiate antagonist naloxone, when administered during the CS-US pairings of the retardation test, attenuated Hall-Pearce LI, but not conventional LI. Young and Fanselow took this as evidence that the two types of LI arise from different associative mechanisms, conventional LI arising from impaired CS processing, and Hall-Pearce LI arising from impaired US processing. This impaired US processing is said to be mediated by conditioned recruitment of endogenous opioid activity when a previously trained CS is paired with footshock, a pairing that does not arise during conventional LI procedures. However, their interpretation encounters two problems. First, they did not include a control group that received pairings of a nontarget stimulus with footshock during the preexposure phase, and one therefore cannot be sure whether the opioid analgesia reversed by naloxone in their Hall-Pearce LI subjects was conditioned to the training context or the CS during Phase 1. If analgesia was elicited by the context, their results would not apply to either the original Hall-Pearce (1979) experiments or our present Experiment $1 \mathrm{a}$, both of which used nontarget-stimulus pretraining as a control treatment and therefore equated associative strength of the context. Second, Young and Fanselow's account involving impaired US processing caused by opioid release predicts that central processing of the nociceptive component of footshock would be attenuated, which might ultimately impair association 
formation. This seems inconsistent with the findings of the present Experiment 1a, in which posttraining exposure to the training context allowed recovery of responding to the target CS.

An alternative to the comparator hypothesis explanation of LI that also depends on CS-context associations is provided by Wagner's (1981) SOP model. In the framework of SOP, pretraining exposure to the CS establishes a CS-context association that, during the subsequent sessions in which the CS and US are paired, allows the training context to reactivate the representation of the CS prior to actual CS-US presentations. This is assumed to decrease the effectiveness of CS processing, and thereby to decrease the degree to which the CS enters into association with the US. In this view, therefore, LI represents a failure to acquire a CS-US association rather than a failure to respond to the CS, as is suggested by the comparator hypothesis. In both the comparator and the SOP models, extinction of the training context prior to the retardation test should degrade the CS-context association. In the framework of SOP, the consequence of this operation should be to enhance subsequent associative processing of the CS, causing better learning of the CS-US association than would otherwise occur. In contrast, the comparator hypothesis assumes that a CS-US association is learned, whether or not context-extinction treatment precedes the CS-US pairings. Nevertheless, the comparator hypothesis and SOP agree that the extinction of the training context between CS preexposure and the CS-US pairings of the retardation test should attenuate LI. Baker and Mercier (1982) and Wagner (1979) have reported data consistent with this prediction (but see Hall \& Minor, 1984).

The comparator hypothesis and SOP diverge, however, in their predictions about the effects of extinction of the training context following the CS-US pairings. As previously stated, the comparator hypothesis predicts recovery of responding to the preexposed CS. The SOP model predicts that this operation should have no effect on LI because LI presumably reflects a weak CS-US association that had been formed previously during the CS-US pairings. The present research was intended to assess these discrepant predictions concerning extinction of the training context following the CS-US retardation-test pairings. To the extent that extinction of the training context after all CS-US pairings is effective in restoring responding to the $\mathrm{CS}$, it would augment the existing evidence that LI represents a performance deficit rather than an acquisition deficit.

Despite the apparent importance of CS-context associations in producing $\mathrm{LI}$, a series of studies by Hall and Minor (1984) might be viewed as inconsistent with the SOP and comparator hypotheses, both of which predict that exposure to the training context between CS preexposure and the retardation test will decrease LI. Those authors varied numerous parameters and failed to obtain the amelioration of LI seen by Baker and Mercier (1982) and Wagner (1979). One problem with extinguishing the training context prior to the retardation test is that the CS is presented in the training context again during the retardation-test CS-US pairings. This may have the effect of causing reacquisition or reinstatement of the CS-context association, which would then result in concomitant retardation. Therefore, extinction of the training context following the retardation-test CS-US pairing, as in Experiments 1 and la of the present series, or presentation of the CS in a nontraining context, as in Experiment 3, may be more suitable procedures for assessment of the importance for LI of CS-context associations.

One interpretation of the present results within an ecological framework has been suggested by David S. Wilson (personal communication, July 9, 1992). During the occurrence of some biologically significant event, such as an encounter with a predator or food source, animals are able to take a memorial "snapshot" of all stimuli present during that event. All stimuli present are equally likely to be associated with that event, although their ability to elicit a conditioned response immediately after the event may be affected by their associative history (e.g., in the present experiments, by whether those stimuli have been encountered previously in that location without any significant outcome). However, because the animal has in memory essentially all information that was presented during the biologically significant event, it is able to reevaluate the relative importance of those stimuli on the basis of information encountered after the event (i.e., by retrospection). In the framework of the comparator hypothesis, reexperiencing other stimuli that were present during the event, without their being paired with any additional significant outcome, allows other stimuli present during the event but not subsequently reexperienced to acquire the ability to elicit a conditioned response. In other words, the causal importance of these other stimuli can be reevaluated upward, on the basis of information encountered by the animal in the same location after the initial event is over. Such a view of postconditioning information processing in general may be a way to understand how organisms continually monitor the causal structure of their environment, using information acquired before, during, and after a conditioning trial.

\section{REFERENCES}

BAKER, A. G., \& MERCIER, P. (1982). Extinction of the context and latent inhibition. Learning \& Motivation, 13, 391-416.

BALSAM, P. D. (1985). The functions of context in learning and performance. In P. D. Balsam \& A. Tomie (Eds.), Context and learning (pp. 1-21). Hillsdale, NJ: Erlbaum.

Bouton, M. E., \& KiNG, D. A. (1983). Contextual control of the extinction of conditioned fear: Tests for associative value of the context. Journal of Experimental Psychology: Animal Behavior Processes, 9, 248-265.

Channeli, S., \& Hall, G. (1983). Contextual effects in latent inhibition with an appetitive conditioning procedure. Animal Learning \& Behavior, 11, 67-74.

HALL, G., \& HONEY, R. C. (1989). Contextual effects in conditioning, latent inhibition, and habituation: Associative and retrieval functions of contextual cues. Journal of Experimental Psychology: Animal Behavior Processes, 15, 232-241.

HALl, G., \& MinOR, H. (1984). A search for context-stimulus associ- 
ations in latent inhibition. Quarterly Journal of Experimental Psychology, 36B, 145-169.

HaLL, G., \& PEARCE, J. M. (1979). Latent inhibition of a CS during CS-US pairings. Journal of Experimental Psychology: Animal Behavior Processes, 5, 31-42.

Hallam, S. C., Matzel, L. D., Sloat, J. S., \& Miller, R. R. (1990). Excitation and inhibition as a function of posttraining extinction of the excitatory cue used in Pavlovian inhibition training. Learning \& Motivation, 21, 59-84.

Kasprow, W. J., Catterson, D., Schachtman, T. R., \& Miller, R. R. (1984). Attenuation of latent inhibition by postacquisition reminder Quarterly Journal of Experimental Psychology, 36B, 53-63.

Kasprow, W. J., Schachtman, T. R., \& Miller, R. R. (1985). Associability of a previously conditioned stimulus as a function of qualitative changes in the US. Quarterly Journal of Experimental Psychology, 37B, 33-48.

Kasprow, W. J., Schachtman, T. R., \& Miller, R. R. (1987). The comparator hypothesis of conditioned response generation: Manifest conditioned excitation and inhibition as a function of relative excitatory associative strengths of CS and conditioning context at the time of testing. Journal of Experimental Psychology: Animal Behavior Processes, 13, 395-406.

Kraemer, P. J., Randall, C. K., \& Carbary, T. J. (1991). Release from latent inhibition with delayed testing. Animal Learning \& $B e$ havior, 19, 139-145.

Lubow, R. E. (1973). Latent inhibition. Psychological Review, 79, 398-407.

Lubow, R. E., SchNUR, P., \& RIFIN, B. (1976). Latent inhibition and conditioned attention theory. Journal of Experimental Psychology: Animal Behavior Processes, 2, 163-174.

MACKINTOSH, N. J. (1975). A theory of attention: Variations in the associability of stimuli with reinforcement. Psychological Review, 82, 276-298.

Matzel, L. D., Brown, A. M., \& Miller, R. R. (1987). Associative effects of US preexposure: Modulation of conditioned responding by an excitatory training context. Journal of Experimental Psychology: Animal Behavior Processes, 13, 65-72.

Matzel, L. D., Schachtman, T. R., \& Miller, R. R. (1985). Recovery of an overshadowed association achieved by extinction of the overshadowing stimulus. Learning \& Motivation, 16, 398-412.

Miller, R. R., BarNet, R. C., \& Grahame, N. J. (1992). Responding to a conditioned stimulus depends on the current associative status of other cues that were present during training of that specific stimulus. Journal of Experimental Psychology: Animal Behavior Processes, 18, 251-264.

MiLleR, R. R., \& MATZEL, L. D. (1988). The comparator hypothesis: A response rule for the expression of associations. In G. H. Bower (Ed.), The psychology of learning and motivation (Vol. 22, pp. 5192). Orlando, FL: Academic Press.

Miller, R. R., \& SChachtman, T. R. (1985). Conditioning context as an associative baseline: Implications for response generation and the nature of conditioned inhibition. In R. R. Miller \& N. E. Spear (Eds.), Information processing in animals: Conditioned inhibition (pp. 51-88). Hillsdale, NJ: Eribaum.
Pearce, J. M., \& Hall, G. (1980). A model for Pavlovian conditioning: Variations in the effectiveness of conditioned but not unconditioned stimuli. Psychological Review, 87, 332-352.

ResCORLA, R. A. (1983). Effect of separate presentation of the elements on within-compound learning in autoshaping. Animal Learning \& Behavior, 11, 439-446.

Rescorla, R. A., \& WAGNER, A. R. (1972). A theory of Pavlovian conditioning: Variations in the effectiveness of reinforcement and nonreinforcement. In A. H. Black \& W. F. Prokasy (Eds.), Classical conditioning II: Current research and theory (pp. 64-99). New York: Appleton-Century-Crofts.

RoBiINs, S. J. (1988). The role of context in performance on a random schedule in autoshaping. Journal of Experimental Psychology: Animal Behavior Processes, 14, 413-424.

SzakMary, G. A. (1977). A note regarding conditioned attention theory. Bulletin of the Psychonomic Society, 9, 142-144.

WAGNER, A. R. (1979). Habituation and memory. In A. Dickinson \& R. A. Boakes (Eds.), Mechanisms of learning and motivation (pp. 53-82). Hillsdale, NJ: Erlbaum.

WAGNER, A. R. (1981). SOP: A model of automatic memory processing in animal behavior. In N. E. Spear \& R. R. Miller (Eds.), Information processing in animals: Memory mechanisms (pp. 5-47). Hillsdale, NJ: Erlbaum.

YOUNG, S. L., \& FANSELOW, M. S. (1992). Associative regulation of Pavlovian fear conditioning: Unconditional intensity, incentive shifts, and latent inhibition. Journal of Experimental Psychology: Animal Behavior Processes, 18, 400-413.

\section{NOTES}

1. The suggestion that posttraining extinction of the context weakens the ability of the CS to activate a representation of the context may seem contrary to the usual operational definition of extinction, in which the signal (CS), not the outcome (in this case, context), is presented alone. However, our thinking is predicated on recent evidence suggesting that associations are bidirectional, with the temporal relationship between the paired events being coded as an attribute of the association (Miller \& Barnet, 1993). Thus, A $\rightarrow$ B pairings likely produce both $A \rightarrow B$ and $B \rightarrow A$ associations (that differ in their temporal attributes), and $\mathrm{B}$-alone (as well as $\mathrm{A}$-alone) presentations will tend to weaken both $\mathrm{A} \rightarrow \mathrm{B}$ and $\mathrm{B} \rightarrow \mathrm{A}$ associations

2 . Actually, the comparator hypothesis would explain the results of Channell and Hall (1983) not by the effect of a change of context on the association between the CS and the training context, but by its effect on the training-context-US association, which would be negated by presenting the retardation-test CS-US pairings in another context. Both the CS-context association and the context-US association must be present for the comparator hypothesis to explain LI.

(Manuscript received January 5, 1993; revision accepted for publication April 2, 1994.) 